\title{
Education and Communication for the Magnetospheric Multiscale Mission
}

\author{
Patricia H. Reiff ${ }^{1}$. Troy D. Cline $^{2}$
}

Received: 8 August 2014 / Accepted: 21 May 2015 / Published online: 17 June 2015

(C) The Author(s) 2015. This article is published with open access at Springerlink.com

\begin{abstract}
The Magnetospheric Multiscale mission (MMS) proposed a balanced portfolio of education and communication activities and products, including broadly distributed materials for the general public, special programs and materials for teachers, targeted activities and materials for underserved groups, and intensive experiences for future scientists and engineers. Our plan includes creation and dissemination of educational software, podcasts and vodcasts, planetarium shows, teacher and student activities, 3D models, social media and smartphone apps. We have surveyed users of NASA data to determine which modes of learning were effective in their youth and which are the most effective now, and use those results to inform our education and communication plans. All materials will be reviewed and placed in NASA online educational archives for broad dissemination.
\end{abstract}

Keywords Magnetism $\cdot$ Education $\cdot$ Communication $\cdot$ Outreach $\cdot$ E/PO $\cdot$ Informal education · Heliosphere - Magnetic fields · Software · Vodcast · Podcast · iBooks · Planetarium · Social media $\cdot$ Underserved students · Teachers · CoSTEM · Next generation science standards $\cdot$ Evaluation $\cdot$ Metrics

\section{Introduction}

The NASA Space Act of 1958 called for the "widest practicable and appropriate dissemination of information concerning its activities and the results thereof" as the third basis for NASA's existence. NASA has been performing educational activities ever since. In 1993, the NASA Space Science Advisory Committee voted to set aside a fraction of each science mission's budget (1-3\%) so that each mission can designate scientists and staff to be able to give more accurate and mission-specific information to educators and the public. In the process an "Educational Ecosystem" was created, with "Forums" organized by

\section{P.H. Reiff}

reiff@rice.edu

1 Rice University, Houston, TX, USA

2 NASA Goddard Space Flight Center, Greenbelt, MD, USA 
Fig. 1 The Education Pyramid seeks to Inspire and Engage many people (through websites and informal education), then Engage and Educate by programs for elementary and secondary students and teachers. For higher education (undergrad and graduate) students, the number reached is far smaller but yields the next generation of scientists and engineers (Employ)

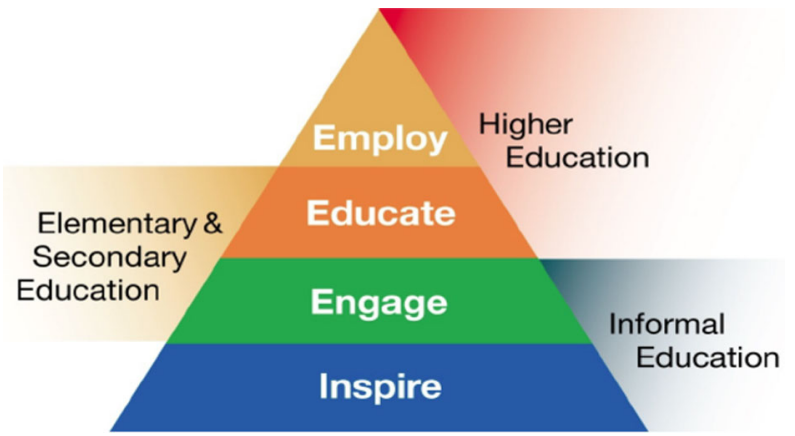

Science Theme (e.g., Solar System, Heliophysics) to oversee, archive, and coordinate activities among the missions. Education and Public Outreach (E/PO) plans then became part of all science mission proposals and were evaluated separately, and the MMS E/PO plan was approved when the science team was selected (GSFC 2001). However, recently NASA is reorganizing the Science Mission Directorate (SMD) Education thrust to be more contentbased and less mission-based. The new initiative, led by the Committee on Science, Technology, Engineering and Math Education "CoSTEM" of the Office of Science Technology and Policy (OSTP), set a new national educational strategic plan which the NASA budgets reflect (OSTP 2013). Thus, not all the efforts outlined here will continue under the new organization.

The MMS (Magnetospheric Multiscale Mission) (Burch et al. 2015, this issue) is a major NASA program focusing on magnetic reconnection, an important physical process observer in the Earth's magnetosphere, the Sun, and many astrophysical objects. It is a "high level" science mission, long on equations and complex high-resolution particles and fields instrumentation and devoid of pretty pictures, so creating educational materials aligned with science standards is a challenge. The purpose of this paper is to present the MMS education plan as it was approved by peer review (GSFC 2001; Burch and Kalmback 2004) during the mission proposal process.

Levels of Engagement: The Education Pyramid Education and Communication are the two new foci of what used to be called E/PO (Education and Public Outreach). This recognizes the two crucial parts of E/PO that must continue even if NASA outreach funding is curtailed: Education (at all levels) and Communication (of science results with other scientists and with the public). NASA (2007) developed the Education Pyramid (Fig. 1), which recognizes that a given project will educate many people to a modest degree, fewer at a middle degree, and the fewest still will go on to STEM (Science, Technology, Engineering, and Mathematics) careers. As the numbers decline however, the intensity and concentration of educational experiences increase, with the next generation scientists spending 5-7 years in graduate school. Without the base of educational opportunities at the lowest levels, however, the mission results will not be effectively brought to the public who paid for the mission.

Lines of Business A more recent organization of NASA communication and education activities is the "Lines of Business" (NASA 2011). At the highest level is "NASA Internships, Fellowships, and Scholarships" (NIFS), which provide opportunities for students to engage in NASA-related experiences as part of their formal or informal education, providing financial support, internships, and workshops. In "NASA Institutional Engagement" NASA creates and develops partnerships with various organizations and educational institutions. In "Educator Professional Development" NASA provides both short and long-term 
development opportunities for K-14 educators. And in "STEM Engagement", NASA uses its unique assets to engage learners of all types, especially underserved communities. Our planned program reaches each of these Lines of Business.

What Do We Want Them to Know? Key to beginning an education and communication program is determining what we want the students to learn at each level. We can't expect a third grader to understand magnetic reconnection, but that student should be able to use magnets to observe that like poles attract and unlike poles repel. The Next Generation Science Standards (National Research Council 2013) form a guide to what is expected of students at various levels. By using NASA examples, we can Inspire and Engage students to learn these topics and see how they apply to cutting-edge research. At the Kindergarten level, a student learns about pushes and pulls and could move something with a magnet; in third grade, students are exposed to magnets and invisibles forces at a distance, and can understand using magnets in daily life; in fourth grade, students learn about types of energy and systems that change energy from one form to another; in middle school, the idea of force fields is introduced; and in High School students create experiments where electric currents cause magnetic field and changing magnetic fields can cause electrical currents. In parallel, students in grade 4 learn about processes that shape the Earth; in grade 5, they learn the basics about the solar system; in Middle School, they learn about gravity and solar system dynamics, and can solve numerical orbital problems in High School. Similarly, the effects of space weather on human systems is a "crosscutting technology" subject. Thus, we have created a system of products to reach learners of various levels and in various venues, including both formal and informal education.

\section{By High School we want all students to know}

1. That the Earth is itself a giant magnet and exerts invisible forces.

2. That the Earth's magnetism protects life on Earth from energetic particles from the Sun and from interplanetary space.

3. That the region controlled by the Earth's magnetism is called the magnetosphere.

4. The Sun emits energy not only in the visible portion of the light spectrum but also in higher and lower invisible frequencies. It also emits plasmas (ionized particles) and, at times, very energetic particles that can be dangerous. That some of the Sun's energy is able to enter the Earth's magnetosphere and powers the aurora.

5. That the gateway to transfer this energy and particles is a universal process called magnetic reconnection.

6. That magnetic reconnection also occurs in the Sun in solar flares and in other astrophysical objects; only near Earth are we able to make the measurements to understand it.

7. That knowing the changes in the electric and magnetic fields in three dimensions in critical to being able to understand the currents and the reconnection process, so that four spacecraft are needed to unfold these changes in space and time.

Similarly, we don't expect that every member of the general public will know each of those items, but it is clearly a goal to do so, and to make materials available so that an interested person can easily find out that information.

It is clear that these topics span all of heliophysics, not just reconnection, the domain of the MMS mission. It is therefore important for us to work with other heliosphere educators to create and sustain a broad program to reach as many of these sectors as we can with accurate, understandable information and inquiry-based tools. With the resources at hand, MMS does attempt to reach as many of these education levels as possible, leveraging resources 
with other programs as much as possible. Thus our plan anticipated the new educational reorganization.

\section{The MMS Education and Communication Plan}

Below we present the detailed plan for the MMS education and communication program, sorted by levels of the "Education Pyramid" (Fig. 1).

\subsection{Inspire-Reaching the Public}

The bottom level of our pyramid is "Inspire"-reaching the average person who has used a magnet on a refrigerator but has no idea of what a magnetic field is. This fits in the "Public Education Activities" portion of the "STEM Engagement" Line of Business. With the rise of GPS technology on many phones and automobiles, the fraction of the public that has used an analog magnetic compass for direction finding has fallen considerably. NASA, with its wealth of new discoveries released daily, is uniquely positioned to inspire the public to learn about science in general and magnetism in particular.

We recently conducted a study of the effect of NASA on inspiring the public to learn about science and/or choose STEM careers, and presented the results at a meeting of the Astronomical Society of the Pacific (Reiff 2013). We sent links to a "survey monkey" survey to users of our educational software, with a control group of adults who are internet-active but not otherwise selected for science interest. In all, we had 162 respondents who were teachers or other E/PO professionals, 41 museum or planetarium educators, 64 other users (students or general public), and 114 in the control group. When asked the premiere question, "have you been inspired by NASA missions?" the results are shown in Fig. 2. Not surprisingly, not many of the general public said that NASA "Changed my life", but it is remarkable that $45 \%$ of them said that NASA inspired them "A Lot" or "Changed My Life". Among the users of our NASA educational products, over $95 \%$ said that NASA inspired them "A Lot" or "Changed My Life".

Planetarium Shows For many, learning in a museum or planetarium is one of the most dramatic ways that students "leave the Earth behind" and encounter the unseen universe. In a planetarium, the students are not distracted by texting or email. They are transported visually and aurally into a black hole, a human body, or the magnetic field of Earth. Thus, these are clearly "Experiential Learning Opportunities" in the "STEM Engagement" Line of

Fig. 2 Survey responses to the question "Have you been inspired by NASA Missions?" Users of NASA data products showed much more influence, but even the control group showed a great deal of NASA influence

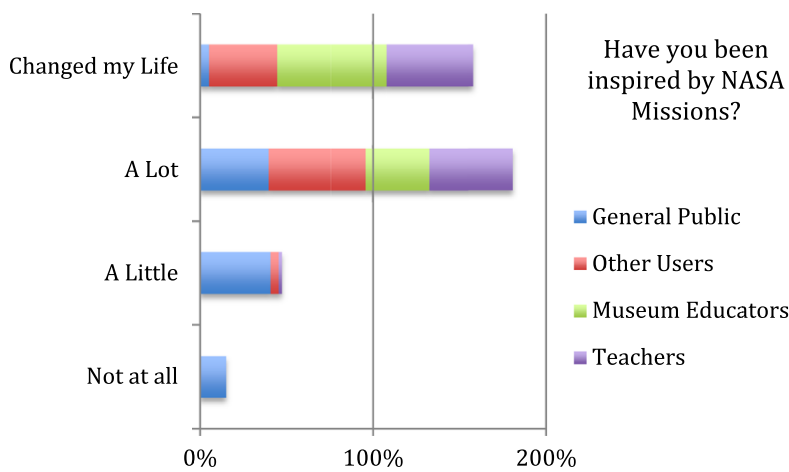


Fig. 3 Visitors in the Discovery Dome at Exploration Station at the AGU meeting learn about how magnetic fields change in geomagnetic storms. (Photo by Gary Wagner, courtesy AGU)

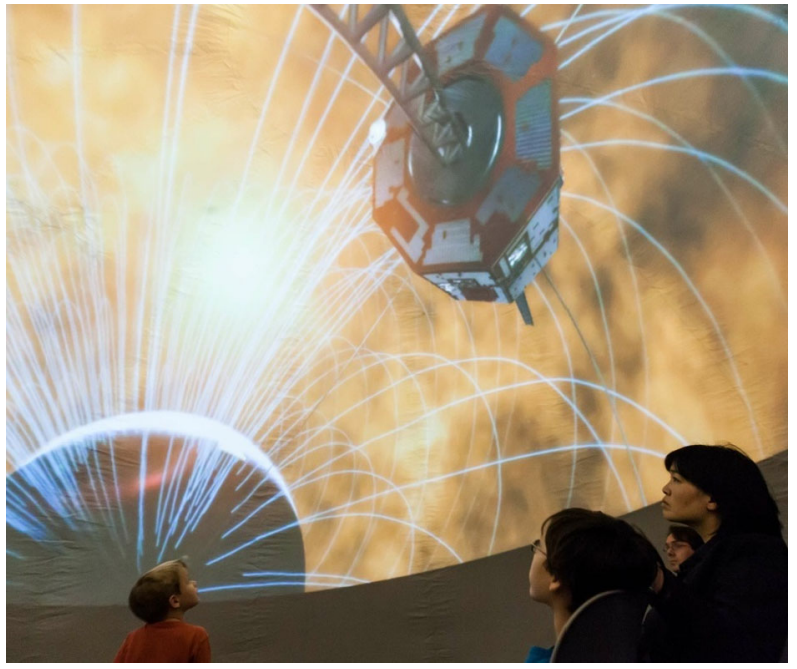

Business. In addition, partnering with Planetariums to create and disseminate these shows falls in the "Institutional Engagement" Line of Business.

Unlike a yet bigger "big screen TV", a planetarium surrounds the visitors, creating a virtual environment. Invisible force fields can be visualized; invisible particles can be animated. Our plan is to create a planetarium show on magnetism, starting with a bar magnet, then showing that the Earth is itself a magnet, then showing how the Earth's magnetic field gets distorted by the solar wind, and finally how reconnection can merge the Earth's magnetic field with that of interplanetary space, allowing transfer of energy and particles from the solar wind to the Earth's environment. We previously created an animation of a solar flare causing a CME (Fig. 3) which interacts with the Earth's magnetic field, as a part of our show "Force 5" (Sumners and Reiff 2010). We will use that footage plus additional footage (computer animations and visualizations) to make a full 20 minute planetarium show to teach about magnetism and magnetic reconnection. We already have one visualization of northward IMF reconnection that was made by Paul Cassak that dramatically shows how field lines get twisted when the IMF has a strong Y-component (available in the Space Update software and also in http://mms.rice.edu/mms/multimedia.php) and we wish to create a similar immersive visualization for more normal southward IMF conditions.

We asked our survey participants as to how they learned about science as a child, and how they prefer to learn about science now. We use these results to inform our educational plans. To answer the question "How did you receive NASA information during your school years?" with multiple responses allowed, the respondents chose teachers first, and informal education venues second and third (Fig. 4). Thus three of our areas of concentration are teachers, museums, and planetariums. When asked the subsequent question, "What is your favorite way to receive NASA information now?", the respondents overwhelmingly preferred the web, but museums, planetariums and TV still scored high (Fig. 5). Teachers also highly preferred $(71 \%)$ learning in workshops or meetings, presumably because of the hands-on training they receive. Thus our program includes hands-on workshops and courses for teachers.

Recent research (Zimmerman et al. 2014) shows that students learn the same material more effectively and retain their knowledge over a longer time when learning in a planetarium dome rather than by watching a video on a computer screen. In a dome, the students 
Fig. 4 Survey responses to the question "How did you receive NASA information during your school years?" Teachers were the first choice for many respondents (nearly $3 / 4$ of the total), but museums and planetariums had an influence on more than half of the respondents

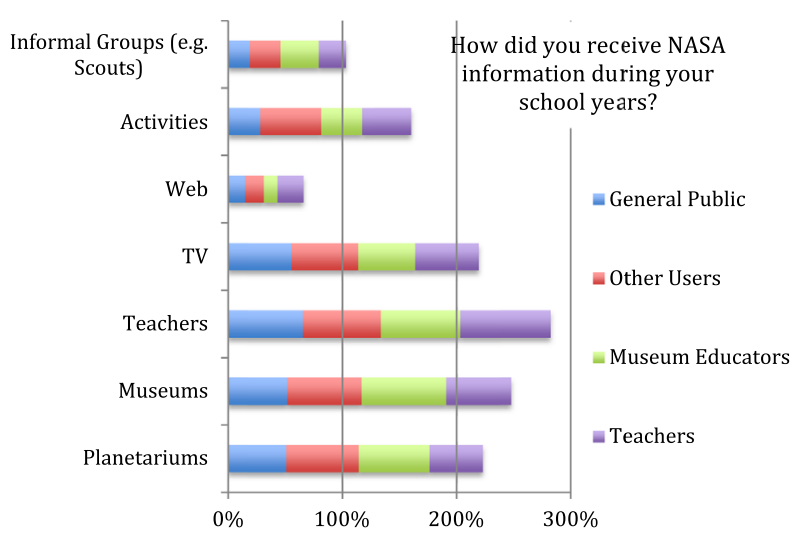

"experience" the material, not just view it, so it becomes stored in both the left and right halves of the brain, making the storage longer lasting.

Museum Kiosk (and Teacher) Software Rice University, in partnership with the Houston Museum of Natural Science (HMNS), developed the world's first internet-updating kiosk, funded by winning NASA's first "Cooperative Agreement" program, Public Use of the Internet. At that time, very few of the public had access to the Internet, so we titled our program "The Public Connection". Under that program, we developed "Space Update" (Reiff et al. 2013), a software suite that brought the best of the web, safely, to museums and schools. Programmed in Macromedia Director, it did not have the risks of an open web browser. That software has been on display at HMNS continuously since 1994, reaching millions of visitors, and is on display at many other museums.

One of the sections of that software, "Space Weather" (Fig. 6), was sponsored first by the IMAGE program and now by the MMS program, and has been given away free to teachers and museums since 2000, as its own disk, first called "POETRY" (the acronym for the IMAGE outreach program), but then changed to the more descriptive name "Space Weather" (Reiff and Law 2014). Over 250000 copies of the "Space Weather" disk, which also includes additional material and activities, have been given away free since 2000, with 195000 distributed as part of the NASA "Sun-Earth Day" packets and the remaining 55000 distributed at teacher meetings and workshops, plus student and public events. In addition, over 64000 copies of "Space Update", which includes the Space Weather module, have been distributed. Both "Space Weather" and "Space Update" have gone through product review and are listed in NASA Wavelength (http://nasawavelength.org), the site for NASA-developed educational products.

Now that many people have faster Internet connections, and to save duplication costs, we now offer the software installer on the Rice MMS page as a free download instead of a physical disk (http://mms.rice.edu/mms/spaceweather_software.php). Once installed, users can quickly download "today's solar images" and "today's space weather forecast". Since the topics are external, it is easy for us to add new science results as they are discovered, and links to the MMS iBook (see description below) and careers videos. Users can "update data" to get the new topics at any time, and we send out notices to our subscribers $(9000+$ teachers, $800+$ museum educators, and $1400+$ general public) when new images or information are released. Thus our networks of users are an effective way to reach thousands of teachers and thus hundreds of thousands of students, in addition to the museums that have the software on display to millions of learners. 
Fig. 5 Survey responses to the question "What is your favorite way to receive NASA information now?". The web is now the choice of nearly $3 / 4$ of all respondents, but TV, museums and planetariums remain a strong influence

Fig. 6 Screenshot from "Space Weather" software showing Jim Burch discussing the MMS mission and what it takes to become a space scientist. The software also has links to the other career videos and to the iBook. It will also have sections on results from the mission and images from the launch
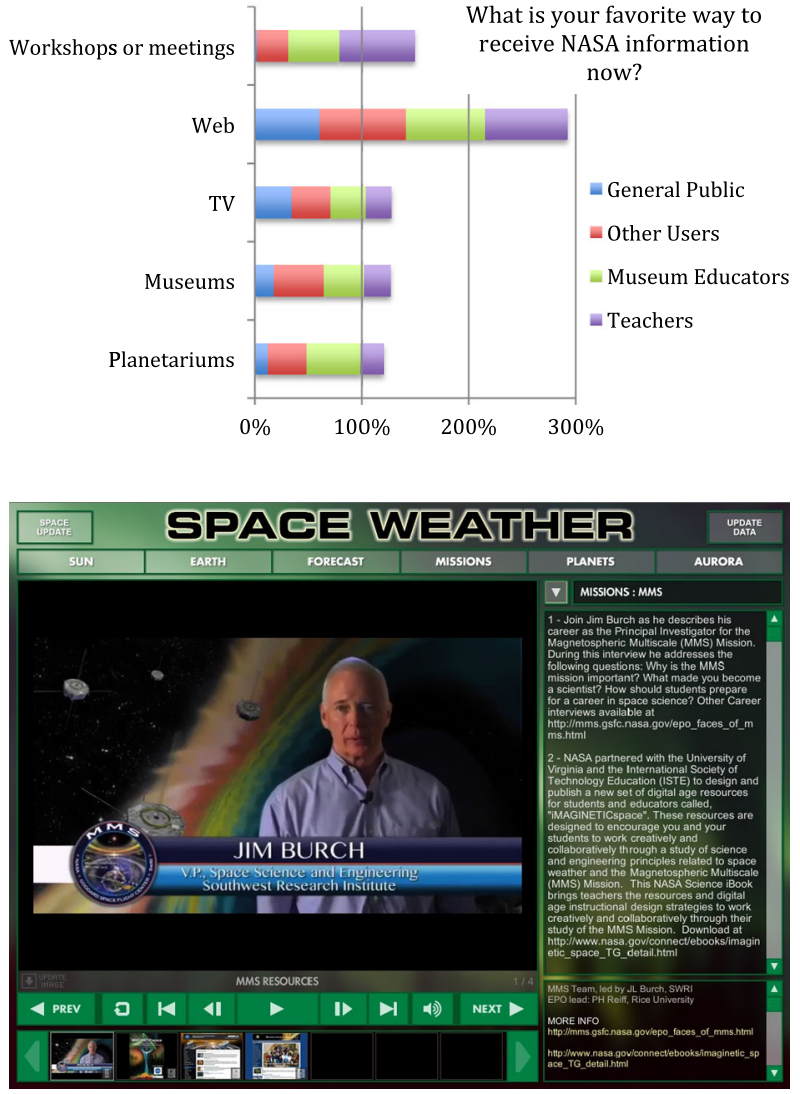

Web-Based Materials Web delivery of educational materials is not only cost-effective but is preferred by most learners today (see Fig. 5). Building a strong reputation as a positive and active contributor to STEM education initiatives requires effective and consistent communication with the intended audiences. Several aspects of the plan support this aim. MMS will work closely with NASA's Office of Communications and existing social media networks to reach our target audiences. The MMS E/PO team is required to maintain and create content for MMS NASA websites, coordinate web page management and graphic design, and ensure that its websites meet usability and other compliance standards. The team must also develop and represent MMS content for non-NASA online informational and social media networks including online tools such as Wikipedia, Twitter, Facebook, YouTube, Pinterest, etc. The MMS plan contains detailed activity descriptions, objectives and outcomes that specify how MMS will leverage the success of new and existing internal and external E/PO programs while remaining the main driver of its own programs.

Both MMS E/PO websites hosted at Goddard Space Flight Center (http://mms.gsfc.nasa. gov/) and Rice University (http://mms.rice.edu) are carefully maintained and cross-linked to provide easy access to educational content. These resources include a growing collection of lesson plans, activities, games, interactives, software, podcasts, video clips and social media links, while highlighting the contributions, accomplishments and career paths of mission personnel. Many of the E/PO materials are designed with the goal of inspiring the next generation to pursue STEM careers. The development of career-related resources (i.e., vod- 
Fig. 7 MMS was featured prominently at the USA Science and Engineering Festival in 2012 and 2014. Troy demonstrated magnetic fields and gave out posters and MMS models and the visitors learned about space storms in the Discovery Dome

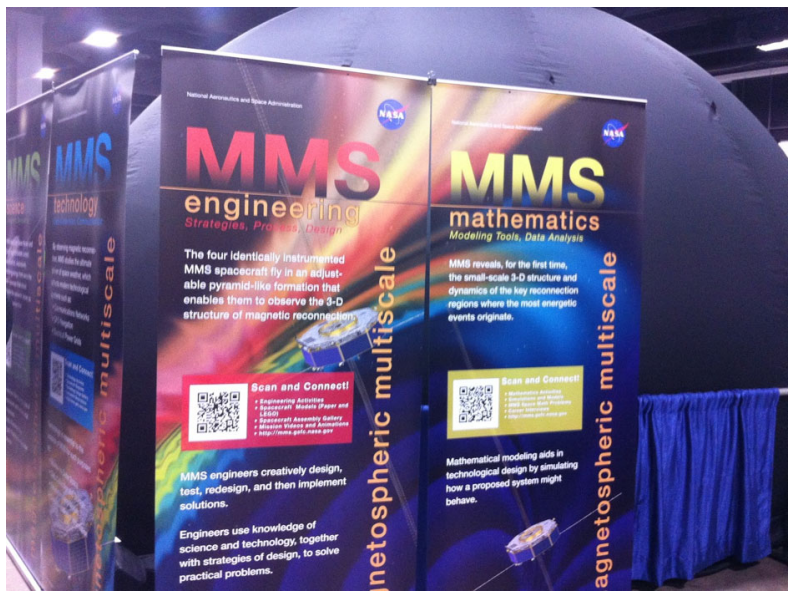

casts, Facebook interviews, images) are linked to materials that support the content of each career being highlighted. As the mission progresses, it is anticipated that these resources will require additional web space specifically designed for a number of MMS E/PO audiences.

By linking directly to existing NASA related websites and programs, the expanding list of MMS online resources are available to audiences around the world. Many of these programs have been designed to place mission materials into the hands of a of target audiences (Formal, informal, community groups, etc.) at a variety of levels (elementary, middle school, high school, college, general public). Additional links provide information about space weather and associated fields of scientific research.

A variety of activities and programs featured on the MMS websites also leverage international programs that engage a large diverse pool of students, educators and general public. Links to high-impact websites and programs include the Sun-Earth Day and NASA Edge programs, science centers and museums, space physics research centers and academic centers (Rice, UC Berkeley, Stanford, West Virginia University, etc.). Many of these stakeholders include education, science, and minority professional societies such as the National Science Teachers Association (NSTA), the Association of Science and Technology Centers (ASTC), Challenger Centers, Girl Scouts (GSUSA), the Astronomical League, the National Society of Black Physicists (NSBP), the Bureau of Indian Education (BIE), and many more.

The MMS team works closely with the Office of Communications during the development of online visualization concepts and tools capable of displaying magnetic reconnection and its impact on Earth's life, climate and technologies. These visualizations will use both real and simulated data, and can make use of MMS data when it becomes available. Our goal is to leverage these types of materials to drive large audiences to MMS resources such as the MMS website, social media pages and other E/PO resources.

Public Events Our project participates in many public events that inspire the public. Some events are co-sponsored with other NASA missions. More recently, because of funding cutbacks, the booth charges for these events are paid for by our partnering outreach corporation, MTPE, Inc., and MMS is welcome to use the event to show displays and distribute materials. These include but are not limited to: USA Science and Engineering Fair (held biannually in Washington, D.C.; Fig. 7); Texas Science and Engineering Festival (held biannually in Austin, TX); World Science Conference (NYC); Sun-Earth Day (at the Houston Museum of Natural Science); and other venues, including dome loans to various small museums. In 
2013, despite the sequestration and government shutdown, our total reach for in-person contact in public venues exceeded 8000 visitors, not counting our events primarily for teachers and for students (see below).

\subsection{Engage}

Program audiences range from the general public to middle school students to pre-service and museum educators, including the underserved and other unique groups. For each of the MMS E/PO projects, products, and activities, the audience is the focus of its design. Careful attention has been given to ensuring that each activity responds to specific audience needs as identified by the greater education community. The MMS plan provides a thorough description of each project, including information on the intended audience, the rationale behind its inclusion in the plan, project design and impact, and linkages to other programs.

Many of the projects contribute to the involvement, broad understanding, and/or training of underserved and/or underutilized groups and make a demonstrable contribution to attracting diverse populations to careers in STEM. Attention has been paid to providing an appropriate pipeline of opportunities that both draws in new audiences and provides opportunities for continued learning beyond the MMS plan.

Public Lectures The entire MMS science team generously gives their time promoting heliospheric science in general, and MMS in particular, at public lectures around the world. As the lead for MMS science education, Dr. Reiff has given a number of lectures, including the "Distinguished Birkeland Lecture" in 2012 at the University of Oslo, and an invited lecture on the aurora and MMS at the SACNAS conference in 2013 and at the Society for Black Engineers in 2011, and was recently the Keynote speaker at the Sigma Xi banquet. Together the team reaches many thousands of learners each year, and these very popular lectures will continue as resources permit.

Social Media Overview NASA projects and activities are required to "draw from audiences that have demonstrated interest in NASA and connect participants to the next level of engagement." The MMS social media program is intended to communicate the science and engineering of MMS, as well as Heliospheric and STEM-related information to the general public and education professionals in an educational, fun and engaging way. Ongoing communication between Heliophysics scientists, educators and the general public is greatly enhanced through a growing social network (Facebook, Twitter, YouTube, Flickr, blogs, Pinterest, Instagram, Wiggio, etc.). These networks excel at user interaction and communication, providing the perfect framework for continual feedback and ideas. They also provide a venue for real-time updates on space weather, sunspots, aurora, E/PO events and missions. Developing and integrating MMS information into these networks will strengthen the relationship we have with our existing community and greatly broaden the reach of our E/PO program.

We take seriously NASA's commitment to accuracy of the information we distribute to social media, and to use social media not to "break news" but to disseminate previously released information to the widest possible audience.

Social Media Objectives The following MMS Social media objectives are closely aligned with the objectives of the MMS EPO program in the following three areas: Overall EPO Objectives, Education Activity Objectives, Public Outreach Activity Objectives. Through a combination of MMS social media outlets with other existing NASA networks, we wish to raise pubic awareness of: 
- The mission's contribution to the greater Heliophysics story

- The science, technology, engineering and mathematics associated with the MMS Mission

- The people involved with the MMS mission, their careers, interests, advice, etc.

- The data results of the MMS Mission.

These objectives are achieved by:

- Sharing relevant mission updates with the general public

- Increasing access to resources on the Web that explain MMS science, instrumentation and careers

- Providing access to multimedia resources that explain MMS science, instrumentation and careers

- Developing and providing visual representations for use in social media venues that explain MMS science, instrumentation and careers

- Engaging outreach professionals about the science and data of the MMS Mission

- Increasing teachers', students' and public knowledge of MMS science, technology, math and engineering

- Reach under-represented and underserved groups (diversity)

- Develop an interest level in MMS that encourages and maintains students' involvement in STEM careers and the pipeline of STEM opportunities.

Social Media Team The MMS Social Media Team implements the MMS Mission's Social Media Strategy, promotes public awareness of the mission and its role in heliophysics, generates inbound traffic, connects content to existing NASA networks and encourages the adoption of outreach materials. The team consists of a Social Media Team coordinator and moderators who coordinate with the GSFC Office of Communications and Social Media teams to support their respective goals while ensuring consistency in voice and cultivating a vibrant social media network. The MMS Social Media Team responsibilities include:

- Working with the GSFC Social Media Lead to ensure

- Alignment with existing NASA social media networks

- Social media tools (for ex. FB connect, Sharing buttons) are kept up to date

- Implementing the social media strategy to ensure its effectiveness while encouraging the adoption of relevant social media techniques

- Managing social media campaigns and day-to-day activities.

- Managing presence in social networking sites including Facebook, Twitter, and other similar community sites, posting on relevant blogs, and seeding content into social applications as needed

- Monitoring effective benchmarks for measuring the impact of social media programs, and analyze, review, and report on effectiveness of campaigns in an effort to maximize results

- Regularly feeding back insights gained from social media monitoring into the team, to help them evolve their strategies in a timely fashion

- Monitoring trends in social media tools, trends and applications

- Manage presence in social networking sites including Facebook, Twitter, and other similar community sites, posting on relevant blogs, and seeding content into social applications as needed

- Becoming advocates of the MMS mission in social media spaces, engaging in dialogues and answering questions where appropriate. 
MMS Social Media Accounts Although our primary objective to drive our audiences to further Heliospheric and STEM-related content, each outlet can have a slightly different purpose depending on such factors as intended audience and/or media used. Together they serve to reach a very wide and broad spectrum of the audience, including people who don't follow any of the MMS or NASA activities. This is accomplished by sparking their curiosity and interest through different approaches. MMS social media accounts include the following:

- Facebook MMS: http://www.facebook.com/MagMultiScale

- Twitter: http://twitter.com/NASA_MMS

- YouTube: http://www.youtube.com/user/nasamms

- Pinterest: https://pinterest.com/mmsmission/

- Facebook Trigger: https://www.facebook.com/Trigger.MMS

- Google+: MMS Google+ activity will be conducted through the existing Goddard Google+ account.

- Wiggio: The Heliospheric Ambassadors use Wiggio for their Community of Practice.

Podcasts and Vodcasts The MMS mission produces a series of podcasts that provide mission highlights, outreach updates and interviews with the MMS family. A Podcast is simply a collection of audio or video content that's powered by subscription software called RSS. Just like a magazine automatically gets delivered to your home when you subscribe, a podcast delivers new content directly to you-without you having to check on the Web site for updates.

Audio Podcasting Program Audio podcasts continue to have a high impact due to users who prefer to listen when video is inconvenient: in the car, at the gym, during walks, in the classroom, etc. There are several distinct advantages to audio-only podcasts: appeals to many listeners, easier content capture, easier editing, easier and faster production, smaller downloads, and cheaper to produce. Due to the linkages to other successful NASA programs such as Sun-Earth Days, it is anticipated the podcasts would receive at least 200000 downloads per year.

In partnership with NASA's existing Sun-Earth Days and Space Weather Living History programs, the team is able to produces an ongoing a series of online audio podcasts (5-10 minutes each) focused on heliophysics topics many of which include MMS mission science and education information. A wide range of content is included: scientist interviews, mission highlights, featured activities, website information, multimedia resources, etc. In addition, links to each podcast are promoted through our partner websites and existing MMS resources.

The E/PO Mission Lead continually works with education specialists to produce primary source activities (activities based on MMS content and research) that instruct users on how to connect the podcasts with other mission resources. All podcasts and activities can be downloaded from a variety of websites including iTunes, MMS, Sun-Earth Days, Space Weather Living History and the NASA portal. All podcasts include transcripts for the hearing impaired.

Video Podcasting and Webcasting Program Video podcasting (Vodcasting) is a great medium through which the general public and students can learn about the MMS mission. Through our partnership with the highly successful NASA EDGE program a variety of vodcasts that appeal to various segments of our intended audiences with the latest MMS developments, issues and $\mathrm{E} / \mathrm{PO}$ resources. 
Fig. 8 Sample NASA Edge program from inside a clean room

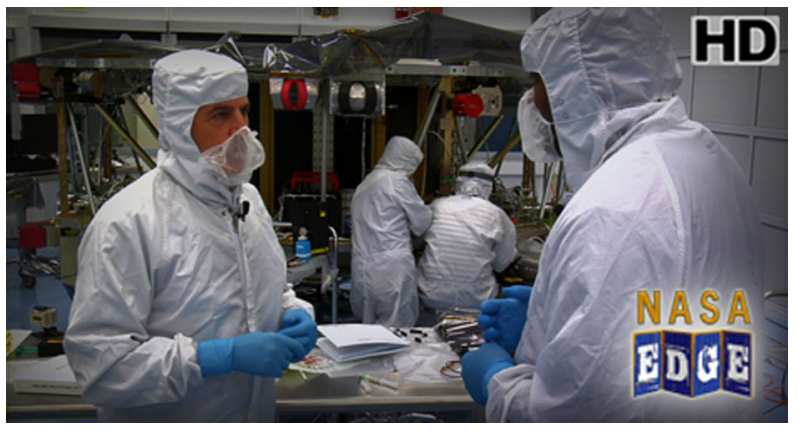

NASA EDGE (Fig. 8) is an unscripted, non-traditional video podcast or vodcast designed to highlight all things NASA in a unique and fun way. Built in the framework of sports talk radio (i.e., Mike and Mike in the Morning-ESPN Radio), NASA EDGE has generated a positive buzz for NASA in a way in which young teens and adults can relate. Their strategy is to inspire the public with multimedia approaches and topics that have an intrinsic interest to the general public. By using a combination of funny, offbeat and informative sketches, features and interviews, the NASA EDGE team created a show that reaches a much broader online audience, surpassing an incredible 18 million downloads since May 7, 2011. As an example of their audience impact, MMS was featured on a NASA Edge vodcast in March 2011 that received over 300000 downloads over a 3-month period. Through this partnership we are able to reach a diverse audience ranging from young students to senior citizens.

Our partnership with the NASA EDGE program includes:

- 1 (20 minute) introductory vodcast that provides a basic understanding of the MMS mission including the MMS goals and objectives.

- 2 (20-25 minute) vodcasts per year that focus on selected topics that highlight aspects of the MMS mission and the people involved.

- 1 (60 minute) live webcast from the MMS launch facility in FY2014. The hour-long webcast will provide the latest updates on MMS up to launch. MMS subject matter experts will join the NASA EDGE Hosts live on set.

- 15 (3-5 minute) 'career based' video podcasts that draw attention to the pipeline of opportunities from which MMS can recruit youth, educators and the public, and to which those who participate in MMS activities can follow up to learn more. This resource titled, 'The Faces of MMS', and all supporting resources appear on the MMS YouTube channel, Facebook, Twitter, Pinterest and the MMS website.

Programs for Underserved Populations MMS has special programs for targeted underserved populations, the groups from which the largest gains in STEM career choices can be drawn in the future. Girls have shown the greatest gains in the past few years, going from less than $10 \%$ of the STEM career workforce in the 70's to $30 \%$ or more today (depending on field). According to NSF (2013), the BA rate for women in the physical sciences has increased from $31.7 \%$ in 1991 to $40.9 \%$ in 2010, and their PhD rate has increased from $20 \%$ in 1991 to $32 \%$ in 2010. The time frame when women and minorities typically lose their interest in science is in middle school (CAWMSET 2000). By targeting these age groups, we open up the flow at the place where the constriction arises.

For girls, we participate in several annual programs: The Sally Ride Science Festival, held at the Rice University campus, reaches over 1000 middle school girls annually (Fig. 9). 
Fig. 9 Peggy Whitson sent a video greeting from space to the girls at the 2008 Sally Ride Rice University festival. The following year, she was the keynote speaker

Fig. 10 Students at the NASA Space Day in Brownsville, enjoying a space weather planetarium show and meeting "Trigger", the MMS mascot, https://www.facebook.com/ Trigger.MMS
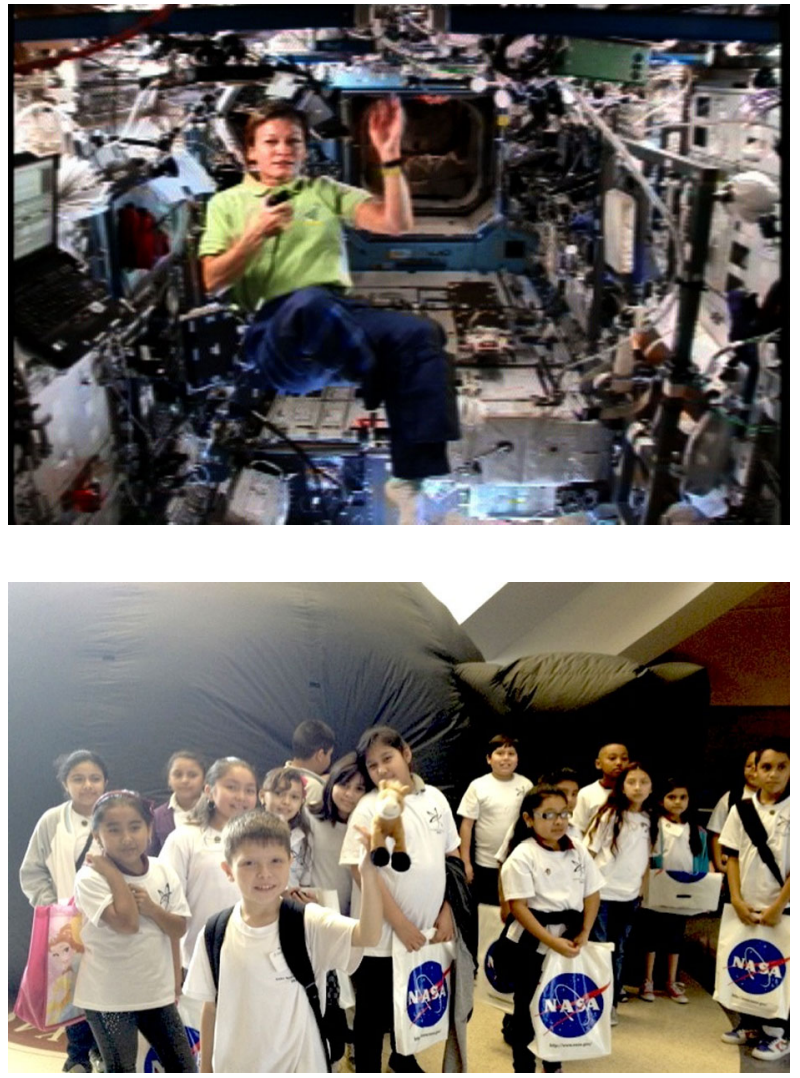

It includes a street fair, an inspiring lecture by a woman astronaut, and two hands-on workshops led by women scientists, engineers, and physicians. This event is leveraged with funding from several cooperating organizations and corporations. MMS distributes the "Space Weather" disc to all participants.

We also participate twice annually in "Solar Week" (http://www.solarweek.org), where students from around the world can ask questions online in the area of solar and heliospheric science. The scientists who answer the questions are all women, providing role models at the same time as the answers to their questions. Other targeted events for girls include partnering with the Girl Scouts at various levels, including summer camps and weekend events.

MMS also has a number of opportunities at various levels targeting minority groups. We participate annually in "NASA Space Day" at the University of Texas/Brownsville (Fig. 10), with a public evening on Friday evening (which reaches over 500 primarily Hispanic families) and a student workshop day on Saturday (which reaches over 600 primarily Hispanic middle school students). We also frequently speak at sessions at professional organizations; for example we have participated in several events sponsored by the Society of Black Engineers, including a keynote talk at the Society for Black Engineers meeting in Austin.

For Native Americans, we frequently have a display at the "SACNAS" conference (Society for the Advancement of Chicanos and Native Americans in Science). In addition, each year MMS sponsors two undergraduate research awards, for the best student poster in space science and aerospace engineering. These awards directly benefit those students who are poised to take the next step in a STEM career. 


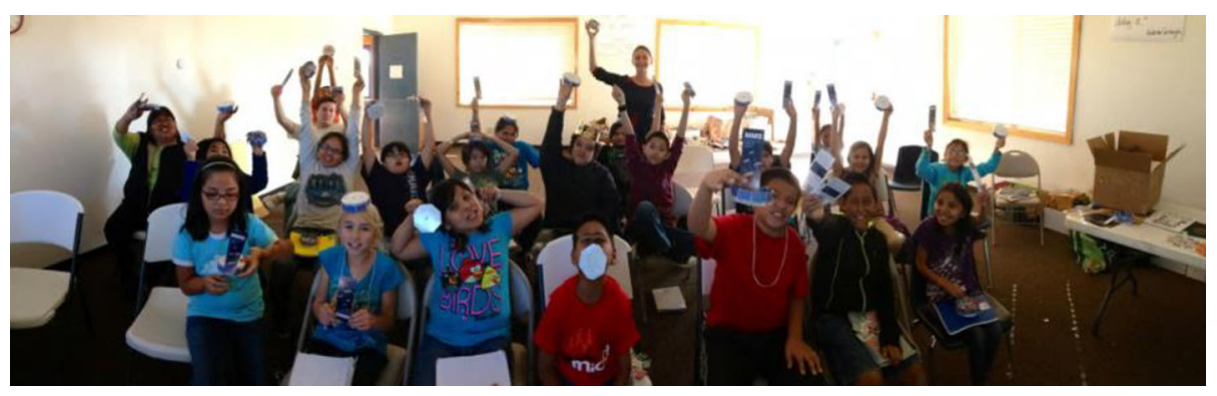

Fig. 11 Students at the STAR School in Arizona

Fig. 12 Students at the "Space Weather Camp for the Vision Impaired" show off the MMS $\mathrm{LEGO}^{\circledR}$ model that they constructed

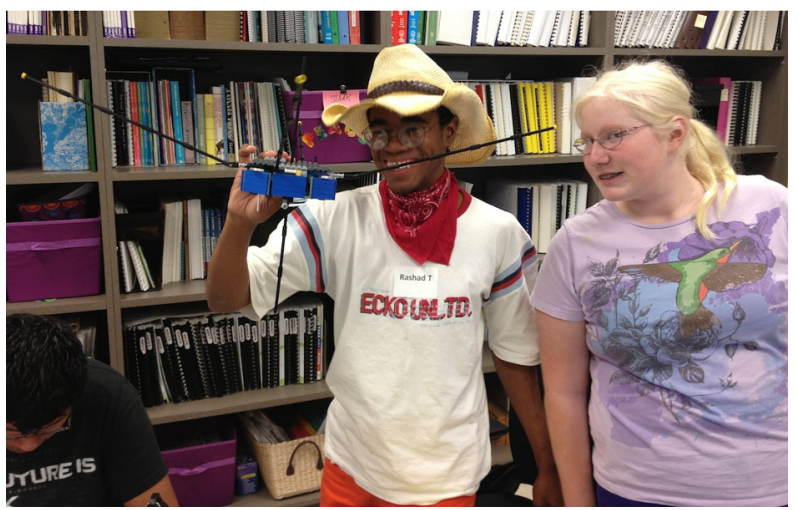

The MMS Mission EPO Lead worked with the Indigenous Education Institute (IEI) to present MMS educational materials to indigenous middle schools in Flagstaff, AZ. In FY2014 both schools and the educational technology representative from the University of Arizona are interested in incorporating the use of 2D and 3D digital fabrication systems in support of the new MMS Transmedia Book. One of the schools, The STAR School, was chosen by MMS to lead a pilot program due to its unique STEM characteristics (Fig. 11). For instance, it is the first pubic school to be completely off the electric grid. This is achieved through hundreds of solar panels and five wind turbines. The MMS Transmedia book provides a needed link between the solar panels used at the school and the solar panels aboard spacecraft such as MMS. The MMS EPO Mission Lead, Troy Cline, is a board member of Indigenous Education Institute and is working with them to develop a series of MMS based workshops that will be shared with various populations around the country.

As a special focus of our outreach efforts, we partnered with the Texas School for the Blind and Visually Impaired to create sonification software and activities appropriate for vision-impaired students. At our "Space Weather Camp for the Vision Impaired", held summer 2013, students built Lego ${ }^{\circledR}$ models of the MMS spacecraft, with the totally blind students sorting the pieces by shape and size and the students with some residual vision using the construction software greatly enlarged to work on assembly (Fig. 12). The students also heard lectures on the "sounds of space"; used bubble paper to use their hands to "view" sunspots and magnetic fields; and wound an antenna and assembled a SIDS receiver.

NASA's Sun-Earth Days (SED) program continues to be a high-impact, mission-first program that has been uniquely successful in keeping heliophysics topics, and its supporting missions, constantly in the public eye. SED's strategy has been to identify annual themes 
that have an intrinsic interest to the general public. They then bring the theme and the issues to the public using media that appeal to various segments of the intended audiences. The MMS E/PO team works with SED team to include MMS materials and resources in existing high impact SED E/PO efforts including SED's Technology Through Time articles, image gallery, video gallery, social media sites and links. MMS leverages the connections already made with the varied communities of enthusiastic teachers and students that make up its inherently diverse audience. To aid in expanding its reach, SED continues in forming strategic partnerships with organizations that can help shape and promote outreach to diverse audiences. These connections create inroads for forming better partnerships within these communities and tailoring more effective SED programs for underserved populations.

\subsection{Educate}

The "Educate" layer generally reaches fewer participants (as is represented by the narrowing of the pyramid) but at a higher, more intense level. For most this means a longer workshop, a series of lectures, a week-long workshop or even an entire semester three-hour course. MMS activities and programs maximize the cost of our given budget by leveraging and combining resources from a variety of groups, programs and partners. Each has a proven track record of effectiveness, as demonstrated in their respective evaluation processes. We are committed to periodic program updates and revisions based upon evaluation metrics that move beyond perception data to monitoring of actual learning in formal or informal environments, as well as the impact of those applications on learning. MMS is working to achieve coherence within the SMD E/PO portfolio and more effective, sustainable, and efficient utilization of MMS science discoveries and learning experiences.

The audiences in this level range from middle school students to inservice, pre-service and museum educators, including the underserved and other unique groups. For each of the MMS E/PO projects, products, and activities, the audience is the focus of its design. Careful attention has been given to ensuring that each activity responds to specific audience needs as identified by the greater education community. Activities as much as feasible shall be aligned with the Next Generation Science Standards (National Research Council 2011, 2013). The MMS plan provides a thorough description of each project, including information on the intended audience, the rationale behind its inclusion in the plan, project design and impact, evaluation, and linkages to other programs.

Many of the projects contribute to the involvement, broad understanding, and/or training of underserved and/or underutilized groups and make a demonstrable contribution to attracting diverse populations to careers in STEM. Attention has been paid to providing an appropriate pipeline of opportunities that both draws in new audiences and provides opportunities for continued learning beyond the MMS plan.

Teacher Programs MMS is the prime sponsor of a major program to increase teacher content knowledge of space science: the Master of Science Teaching program (http://space.rice. edu/MST) at Rice University. This program supports a four-course series of 3-credit hour classes for teachers. Designed for middle- and high-school teachers, one course PHYS 501 "The Physics of Ham Radio", also draws a significant number of students from the Rice undergraduate and graduate program. That course teaches circuits, waves, and antennas, plus the ionosphere, the Sun, space weather and the magnetosphere. The students receive their "Technician" class ham radio license and learn a lot about space in the process. The other courses sponsored by MMS include ASTR 502: "Teaching Earth and Space Science" and ASTR 503: "Astronomy for Teachers". The fourth course, ASTR530: "Teaching Astronomy 
Lab" is paid for by the teachers. The teachers can choose research or other relevant courses to fulfill the 30 hours needed for the MST degree. These courses have a substantial discount: MMS (or the teachers themselves) pay only $\$ 1200$ tuition per three hour course, and the remaining $\$ 5800$ tuition for each is a Rice University contribution. As of 2015, 27 teachers have graduated from the program with four presently in progress.

We have recently made these courses more national by encouraging teachers to participate remotely using an online synchronous system. We surveyed 200 potential participants, and received the following results: Would you be interested in a hybrid system, one two weeks in the summer (group meeting) followed by remote participation courses? Definitely yes: $71 \%$; Possibly yes $25 \%$; Probably not $1.5 \%$. When we asked about fully online courses with no live human interaction, the group was much less enthusiastic: Definitely yes: $27 \%$; Possibly yes: $46 \%$; Probably not: $21 \%$; definitely not: $4 \%$. Teachers clearly appreciate getting hands-on instruction for themselves just as we recommend that they use hands-on inquiry-based instruction for themselves. We have now run ASTR 503 and PHYS 501 as test-case courses with remote participation and the results have been very satisfactory, with many teachers just participating for "Certificates of Completion" but some receiving course credit as remote participants.

Teacher Events MMS participates in regional and national teacher events, both as part of NASA booths (where we demonstrate and give away our software) and also partnering with our corporate partner, MTPE, Inc. We typically reach several thousand teachers a year at the National Science Teachers Association (NSTA), the Texas Conference for the Advancement of Science Teaching (CAST), the International Society of Technology and Education (ISTE) and at other national and regional teacher meetings. As a result, more than 9000 teachers are active in our "e-teacher" email network, where we send out weekly notices of NASA science results and teacher workshop opportunities.

Educator Materials, Resources and Activities The following list of materials, resources and activities were developed with the following objectives in mind:

- Engage middle and high school students in learning MMS science and instrumentation

- Develop an interest level in MMS that encourages and maintains students' involvement in STEM careers

- Educate in-service and pre-service teachers (face-to-face) in MMS science

- Educate in-service and pre-service teachers (virtually) in MMS science

- Provide access to MMS data to diverse audiences that contribute to the involvement, broad understanding, and/or training of underserved and/or underutilized groups.

LEGO Models of the Spacecraft with Educator's Guide MMS worked with designers, developers, NASA scientists and engineers, and students from West Virginia University's MARS LEGO team to collaborative design and develop the model (Fig. 13). Once the model was created and building was tested, it was released to the public through social media channels and the MMS website. A Pilot workshop with LEGO models and the MMS Math Guide was completed at the West Virginia Educator Resource Center (12 educators); 5-6 additional workshops are planned for FY2014 involving 80 educators, models and math guides in WV. Additional workshops are being planned for the states of Pennsylvania and Texas. 
Fig. 13 LEGO $^{\circledR}$ model of the MMS Spacecraft

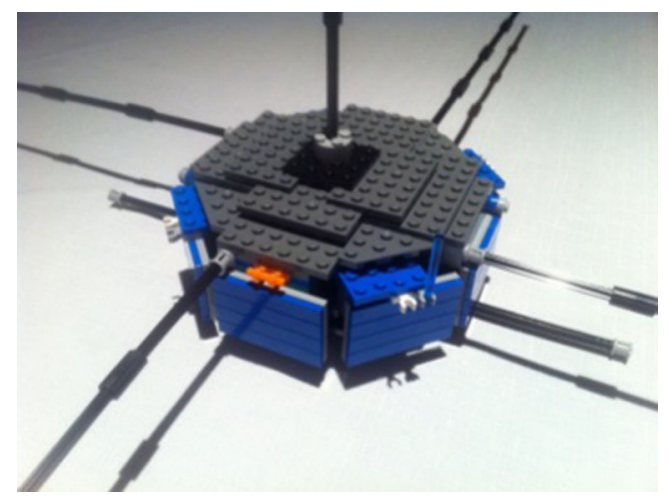

Fig. 14 Space Math problems focused on MMS

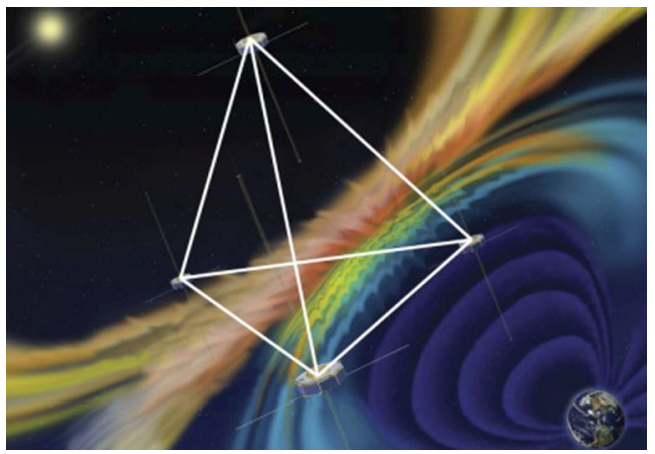

Space Math Activities and MMS Spatial Geometry Guide In 2012, NASA's SpaceMath program and West Virginia University developed a 75-page educators' guide with seven MMS STEM based problems (Fig. 14). This guide uses examples from the MMS Mission to introduce mathematics in a real-world context to fifth through eighth graders is meant to help students learn about math utilizing the NASA MMS mission. The guide focuses on two-dimensional and three-dimensional geometry to assist students in developing spatial skills. There are also some activities that involve algebra and computational skills. The four lessons are: (1) Model of the MMS Satellite, (2) Launch of the Satellites, (3) The Satellites Flight Configuration, and (4) Powering the Satellite.

Bookmark/Paper Model Activity This easy to do activity combines an MMS bookmark with a $1 / 30$-scale model of the MMS spacecraft (Fig. 15). Users can also find important URLs and QR codes for quick access to additional information about the science and engineering of the mission. The pattern for the model can be downloaded from http://mms.gsfc. nasa.gov/epo_mms_paper_model.html.

Tetrahedron Model with Maxwell's Equations In our website (mms.rice.edu), we have materials to help teach Maxwell's equations based on graphical representations of the divergence and curl. For younger students, we created a simple activity to create a tetrahedron model of the spacecraft positions, with Maxwell's equations on the vertices (Fig. 16). Download via http://mms.rice.edu/mms/tetrahedron.php. 

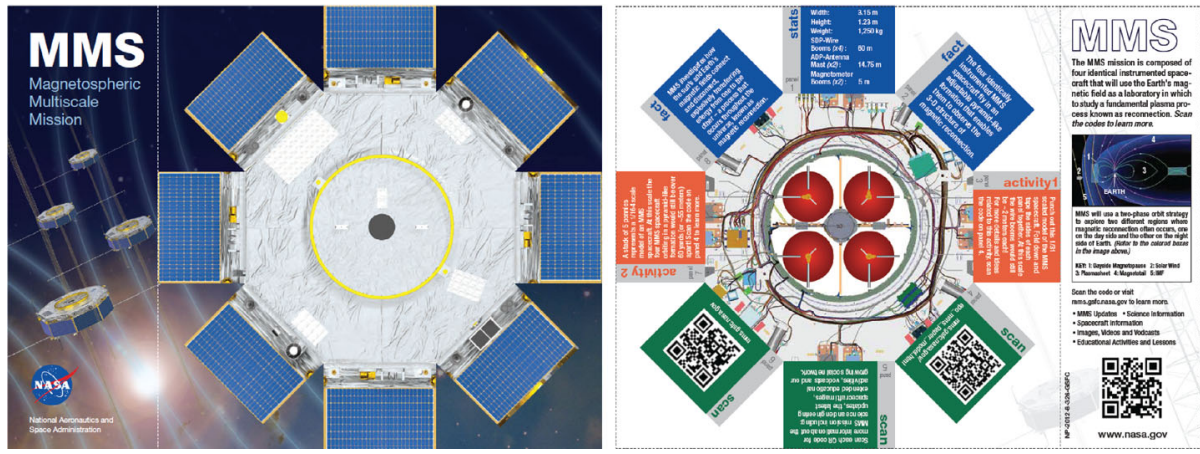

Fig. 15 Paper model of the MMS spacecraft (left, front; right, back). The edge strip becomes a bookmark

\section{Museum Kiosk (and Teacher) Software: (See “Space Weather” Described Above)}

Space Weather Action Center From 2009-2013, MMS completed 11 activities related to the Space Weather Action Center. Activities included developing a mobile Space Weather viewer, holding workshops on using the viewer, working public events as a representative of MMS, preparing accompanying educational materials, and participating in broadcast events having a national reach.

Cyber Café In collaboration with ISTE, the Cyber Café, a seminar for educators to learn about MMS was offered to 25 educators who worked in seven teams to create learning activities. Several of the learning opportunities developed through the Cyber Café will go through product review and reach hundreds of educators through NASAwavelength.org.

'Take the MMS Challenge' Project Teachers involved in the Cyber Café project created a project called "Take the MMS Challenge" which encourages students to solve a mission based problem from the perspective of a chosen career: science, technology, engineering, arts, mathematics. The project was successfully passed NASA's product review and was piloted with over 2000 middle school students at the Dublin School District in Texas. Additional workshops are being planned for 2014 .

MMS Career Videos This growing list of STEM based career interviews enables students to take a quick peek into the lives and careers of the extraordinary people who make up the Magnetospheric Multiscale (MMS) Mission (Fig. 17). Educational activities are being developed and/or modified to promote the series in classroom environments: (1) Careerbased Bulletin Board Activity, (2) Take the MMS Challenge, (3) iBook Resume Builder. The series has already receive over 6500 downloads.

iMAGiNETICspace Project MMS partnered with the University of Virginia and the International Society of Technology Education (ISTE) to design and publish this new set of digital age resources for students and educators called, "iMAGiNETICspace" (NASA 2012) (Fig. 18). These resources include a 'Student Transmedia Book' and an 'Educators iBook Companion'. Both resources are designed to encourage educators and students to work creatively and collaboratively through a study of science and engineering principles related to space weather and the Magnetospheric Multiscale (MMS) Mission. More information and downloads available from http://1.usa.gov/105xvtA. 


\section{The MMS MaXwell Tetrahedron}

A Tetrahedron is a regular solid (pyramid), with four vertices and four faces. Each face is an equilateral triangle. The MMS Tetrahedron has four vertices, one for each of the four spacecraft (shown here as blue, red, gold, and green). The spacecraft fly in a tetrahedral formation, so that they can best measure the time and space changes of the fields and particles the group flies through.

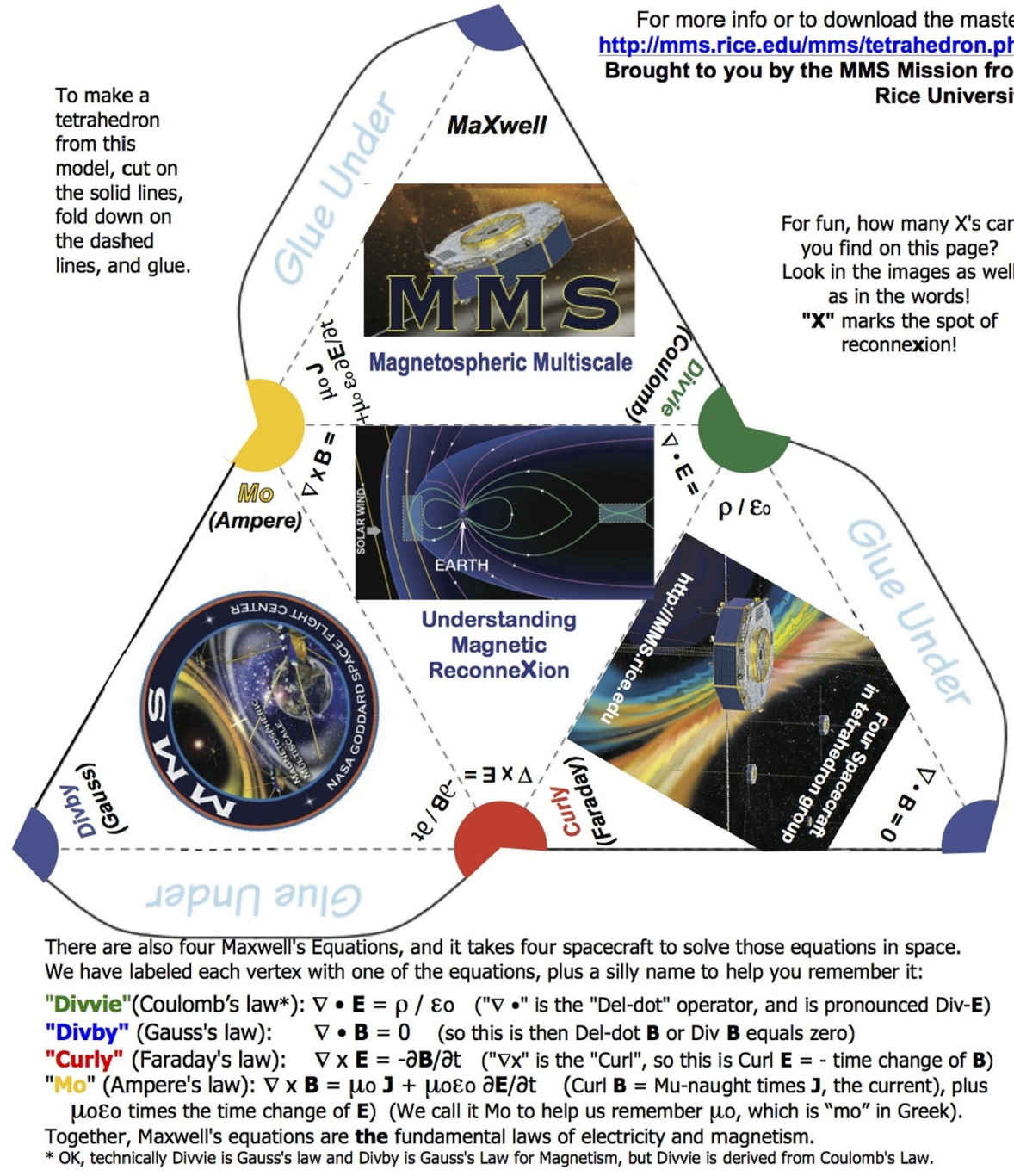

Fig. 16 Pattern to create an MMS tetrahedron with Maxwell's Equations on the vertices

The Student Transmedia Book (T-Book) is a digital age storybook designed to help students learn about the NASA's MMS mission through a variety of inquiry and engineering based experiences. It includes experiment instructions, data collection tables, reflection activities, QR codes linking to MMS content all while encouraging the use of digital fabrication. Implementation with 311 8th grade students from two middle schools in Harrisonburg, Virginia also showed positive gains in content knowledge and STEM career interest and dispositions (Christensen and Knezek 2013). 
Fig. 17 Image from one of the career videos
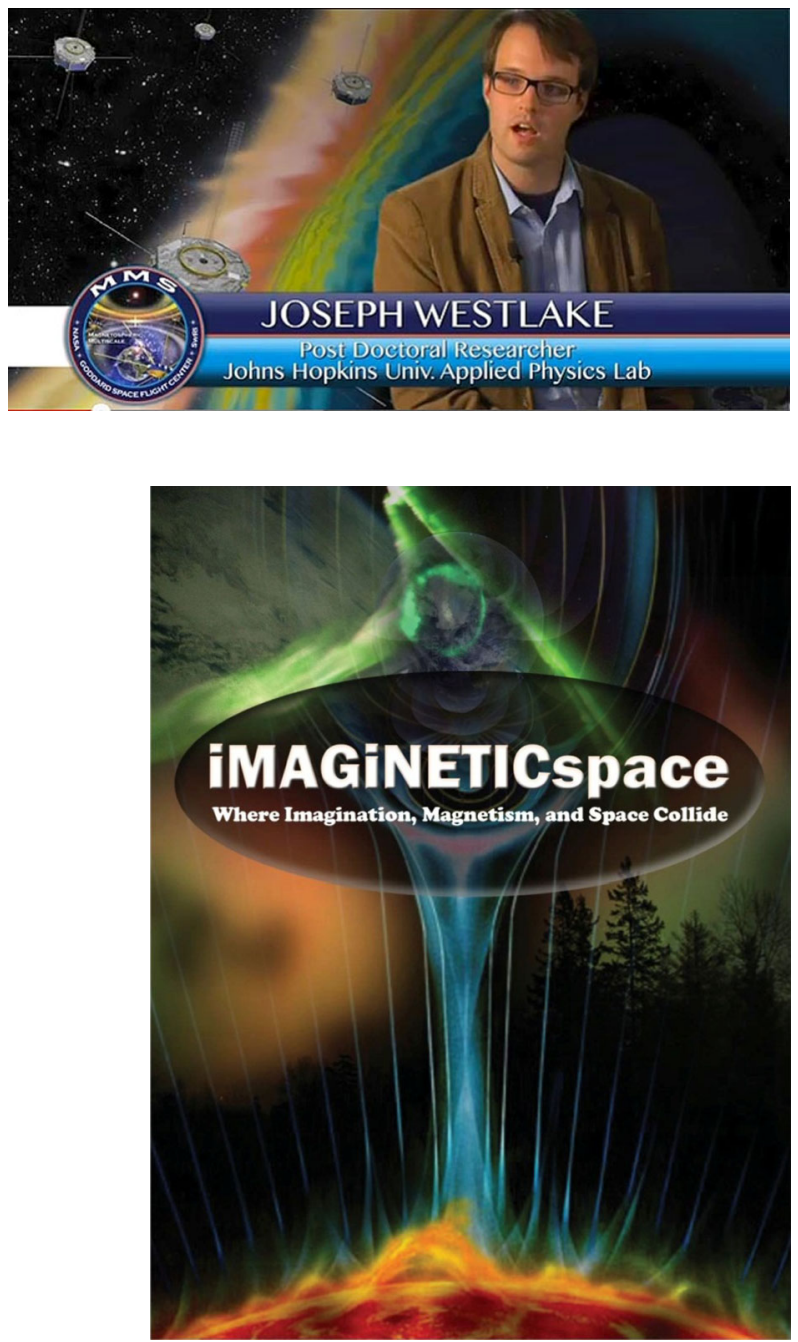

Fig. 18 Cover of the award-winning transmedia book, available in several versions for free download

The Educators' iBook Companion is a mobile resource for the iPad embedded with selfpaced professional development tools, information, and resources for educators. It adds a new timely multimedia dimension to learning by allowing users to explore tributary information that supplements knowledge and understanding of content presented in the student T-Book. The iBook authors created rich learning content embedded with text, audio, and video that is well suited for complex concepts or demonstrations. The iBook is embedded with:

- Interactive content from NASA's Magnetospheric Multiscale (MMS) Mission and Space Weather Action network websites

- Tutorials that demonstrate how to modify extension activities for a broad range of students with various backgrounds and experience. (This broadens the range of student ages suitable for this instruction-making learning activities simpler for younger students and more complex for students who excel at the STEM disciplines.) 
- Lesson and experiment extensions that are aligned to the Next Generation Science Standards and the National Educational Technology Standards (NETS).

- Self-paced professional development tools for teachers seeking to enhance their digital age teaching skills.

MMS Digital Fabrication Schools To engage the K-12 community and the public with the MMS mission, NASA, the University of North Texas, and Dublin Independent School District are proposing to implement a STEAM (Science, Technology, Engineering, the Arts, and Mathematics) program to include the arts using an advanced fabrication technique known as 2D and 3D printing to promote excitement surrounding NASA's MMS 2014 mission, space weather, engineering, Magnetospheric Physics, and introducing students to STEM career pathways. A pilot study showed statistically significant $(<0.05)$ pre/post test gains in 79 4th and 5th graders' in engagement in science and problem solving (Knezek et al. 2013).

Over 20 schools have already received 2D and 3D digital fabricators. Beginning in the fall of 2013, student productions and reflections will be shared with a larger community to include both educational and public outreach events. The program will provide a series of educator workshops to the global community leveraging the recently produced MMS Educator Guide, the MMS Challenge, the MMS Transmedia Book and promotion of the integration of the MMS career video series into K-12 learning. Several professional development workshops will be held during and after the STEAM program to share best practices to an international community of K12 educators and stakeholders. By the fall of 2013 the school district will implement a fabrication 3D printing program in their existing Computer Technology and Engineering (CTE) courses and a 2D printing course in most of their Math/Science classrooms.

STEAM Camp Dublin ISD piloted the MMS Challenge during the summer STEAM camp of 2012 and hosted a NASA national student summit in April of 2012 to help generate excitement about NASA's MMS mission. Student experiences included hosting a digital art, physics, and robotics exhibition. Although Dublin ISD is a small and rural school, the impact of DISD STEAM camp led to an after school robotics program during the fall of 2012. Dublin ISD is now extremely active in STEM activities both during and after-school. The NASA MMS Challenge was piloted in Dublin ISD during the spring of 2012 and during Dublin ISD's STEAM 2012 camp. The program was featured at ASCD 2012 fall conference, ISTE 2012, TCEA 2013, and was showcased at SITE 2013 and ISTE 2013. This program provides Dublin ISD and NASA the opportunity to extend on the previous experiences to focus on solar renewable energy and to pilot a fabrication unit to build academic vocabulary relating to renewable energies, solar weather, and magnetic space topics.

Life-Size Student Model of the MMS Spacecraft To engage the K-12 community and the public in the MMS mission by designing a full-scale model of the MMS spacecraft for both educational and public outreach events, providing a series of educator workshops leveraging the recently produced MMS Educator Guide, and promoting the integration of MMS learning activities at the National Science Teachers Association annual conference. High school students from the Mountaineer Area RoboticS (MARS) FIRST Robotics team, who have recently developed several LEGO ${ }^{\circledR}$ MMS models, will mentor and guide 6-12 grade students from the state's second smallest K-12 school in Paw Paw, West Virginia in the design and construction of a full-scale model of the MMS spacecraft. Paw Paw students and their teacher who spent the FY2013 school year studying space weather traveled to San 
Fig. 19 Students in Ipad workshops

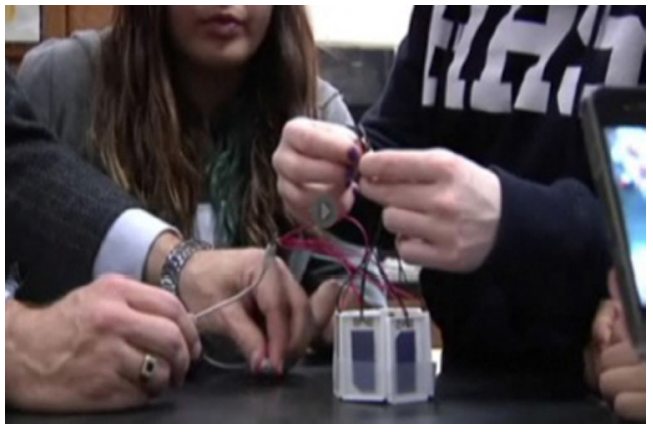

Antonio, Texas to present MMS materials at the National Science Teachers Association annual conference. Through both the full-scale model construction and the national conference presentation, this project will be directly strengthening NASA and the nation's future workforce. Through the delivery of a series of teacher workshops across the state of WV and the development of a professional development module, this project will provide the resources to educators to attract and retain their students in science, technology, engineering and mathematics (STEM) disciplines. When completed, the student-built full-scale MMS model will be delivered to the Clay Center for the Arts and Sciences in Charleston, WV where it will be put on display allowing this project to engage countless Americans in NASA's mission for many years to come.

MMS STEM and Educational Technology Based Workshops Spatial Geometry and Model Building Workshops: A series of ongoing educator workshops were developed and tested at NASA's IV\&V Educator Resource Center (ERC). Each workshop includes the use of educator iPads (Fig. 19), MMS content, Space Weather Action Center resources and the MMS Spatial Geometry Math Guide. Six additional workshops are being planned for the state of West Virginia that will initially involve over 80 educators and their communities. Templates of this series of workshops are being developed and will be shared online.

MMS Educator iBook and Design Challenge Seminar: This seminar consists of a series of 4 educator workshops that were developed in partnership with the Lincoln Intermediate Unit in Pennsylvania. The Lincoln Intermediate Unit serves local schools and communities, local businesses and nonprofit organizations, all Pennsylvania schools, Intermediate Units and libraries via statewide programs, and federal, state and local agencies. The seminar showcases STEM components of the MMS mission by focusing on activities and programs found inside the new MMS iBook: 4 design challenges, MMS science content with invited speakers and educational technology extensions developed by the International Society of Technology and Education (ISTE). Each workshop in the series hosts no less than 60 students, parents and teachers with an extended impact of 2000 4-8 grade teachers in Pennsylvania. Templates of this series of workshops are being developed and will be shared online.

Extreme Weather Workshops: 4 joint educator workshops between the MMS and GPM (Global Precipitation Measurement) missions were conducted with over 100 educators that included virtual scientist talks, Q\&A, and hands-on activities. These workshops focused on extreme weather events found in space and on Earth, and taught participants about the science and engineering behind both missions. We worked closely with the Goddard Space Flight Center Office of Education and started development of an online course component. 
Fig. 20 "SMART" students at UNH launch their science experiments on a high-altitude balloon

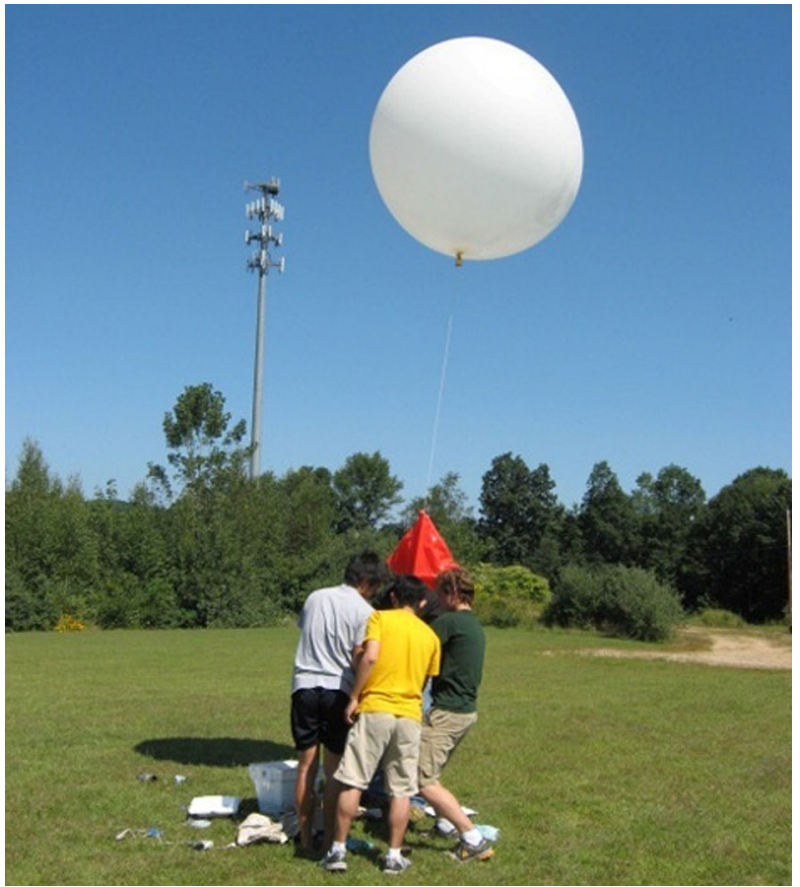

\subsection{Employ}

The "Employ" level, at the peak of the pyramid, reaches the fewest students but at the most intense. Here, higher level students receive extended training, either in longer summer workshops, or in graduate schools. Most of the University MMS teams are bringing graduate students into the project. Some have been with the project through its instrument design and construction. Others have worked on software design for the data centers and SITL functionality. Still more will be the ones who get their hands dirty in the analysis of MMS science, gaining vast experience and a Ph.D. in the process.

Summer Student Workshops MMS sponsors two major summer High School student workshops: "SMART" at the University of New Hampshire (http://www.smart.unh.edu) and "YES" at the Southwest Research Institute, San Antonio, TX (http://yesserver.space. swri.edu). "SMART" brings together 20 students from across New Hampshire for a fourweek program. The "Space Science" track, sponsored by MMS, typically has 4-6 students who learn about space physics, and space experimentation, which they then build and fly in an upper atmosphere balloon flight (Fig. 20).

At SWRI, the YES program annually brings 20 local high school students and selected teachers together to learn about space science and space instrumentation in a 2.5 week program. They hear from MMS scientists and engineers about the science behind the mission, and see actual flight hardware being built and tested. They do hands-on instrumentation construction. Each year the Discovery Dome comes to San Antonio to bring a little more inspiration to these talented and eager students (Fig. 21).

Graduate and Postgraduate Student Programs The primary payoff for any NASA mission is the scientific understanding it brings to the field. For the MMS team members at Uni- 


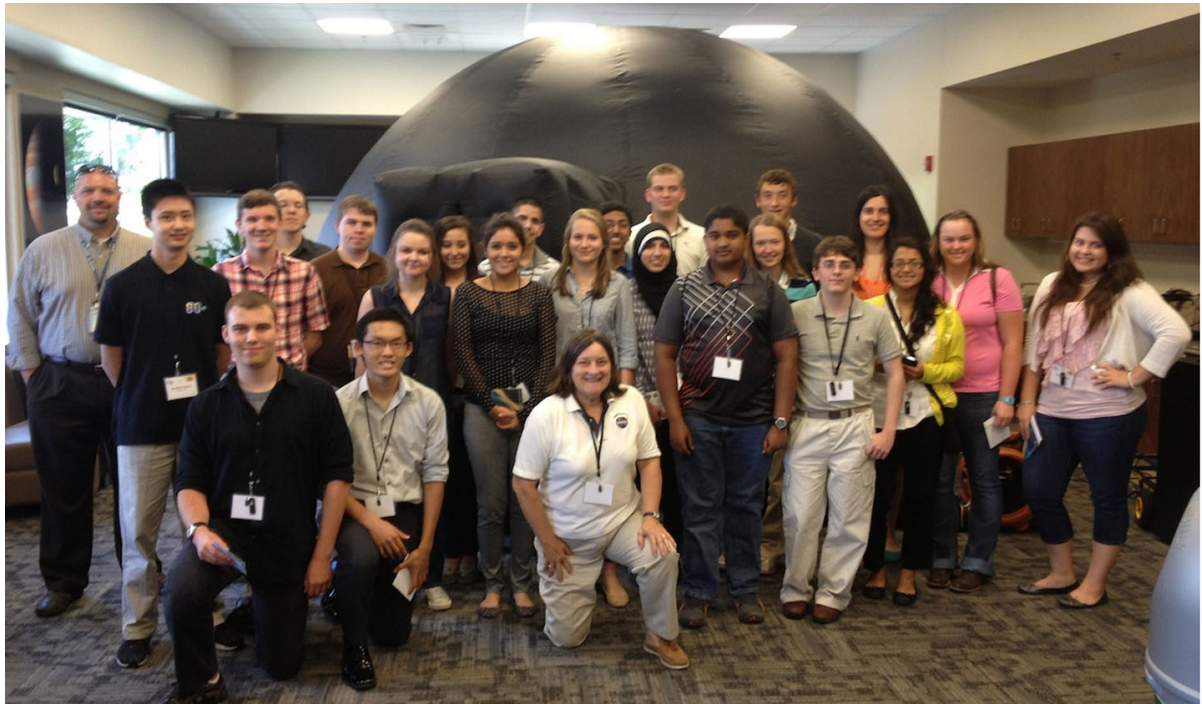

Fig. 21 "YES" students at SWRI experienced a solar storm in the Discovery Dome after hearing a presentation on space weather and the MMS mission by Dr. Reiff

versities, a large part of the theoretical modeling and data reduction and analysis is done by team members working with undergraduate students, graduate students, and Post-Doctoral students. These are the "peak" of the education pyramid and have the deepest investment in mission resources, and the most influence on the students, who for the first time become real scientists on their own. In addition, NASA centers such as GSFC also employ Post-Doctoral students to aid with the data analysis and theoretical interpretations.

Funding for these higher-level students does not come from the E/PO line but from the science analysis line, through the individual institutions represented on the science team, including Dartmouth, Rice University, UC/Berkeley, University of Colorado, University of Iowa, University of New Hampshire, University of West Virginia, and several international institutions, We anticipate that at least 20 students will receive Ph.D. degrees as a result of the MMS program reaching its scientific objectives.

\section{Evaluation and Dissemination}

No NASA Education and Communication program would be complete without an evaluation component. Our evaluation consists of several stages:

Metrics Usage metrics of our various populations served are collected for each event and annually put into the NASA "OEPM" metrics service, separated by, e.g., educators, students, public, direct users and other users (for web materials).

Product Evaluation Each product we develop is submitted to the NASA Product evaluation, where it is evaluation for accuracy and effectiveness by a team of scientists and educators. Each item is linked to the primary "Next Generation Science Standards" (NAS 2013) that it covers. Successful products are then placed into "NASA Wavelength" 
Fig. 22 The results of our survey show that the respondents are overwhelmingly in favor of NASA continuing to produce educational materials and planetarium shows

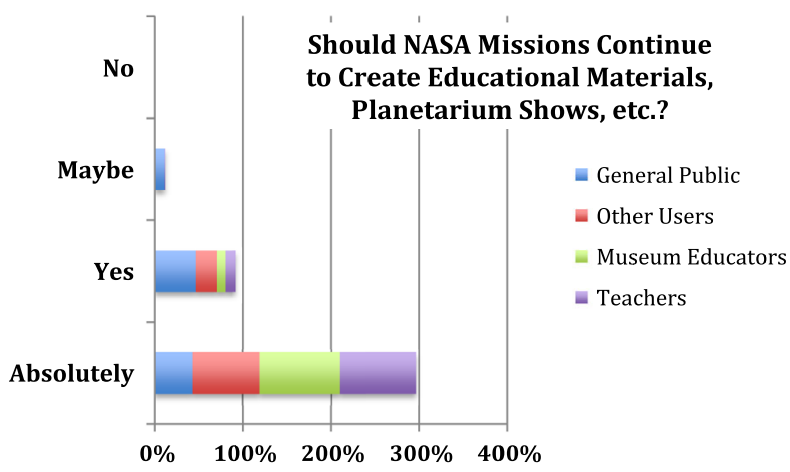

(http://www.nasawavelength.org) for wide dissemination. We have created a "MMS" list of NASA wavelength activities.

External Evaluation The MMS project has hired Hilarie Davis as our external evaluator. Dr. Davis of "techforlearning.org" is an experienced evaluator who routinely works with NASA outreach programs, including the forums. She is well versed on the needs of the various communities we serve (Davis 2013)

Additional Dissemination All web materials are also available through the MMS web sites at NASA and at Rice University (http://mms.rice.edu). Educational software and links to resources are also given away at NASA booths and through booths paid for by our partner outreach company, MTPE, Inc. Web statistics are reported for usage of these resources.

\section{Conclusions}

It is clear from the success and popularity of our efforts that this balanced program will reach a variety of audiences with age-appropriate material. It is clear from our surveys that users of the NASA data and the public are tremendously in favor of continuing NASA outreach (Fig. 22). MMS will continue to work closely with other NASA Heliospheric programs through the Heliophysics Forum and other activities of the SMD education groups. We participate in all SMD workshops and telecons. We are also working with the new federal "COSTEM" program which seeks to coordinate and collaborate across federal agencies.

We will promote our projects to museums through the "Museum Alliance", and will list our products through NASA Wavelength. The proposed E/PO schedule and activities outlined in our original proposal, and elaborated here, will clearly have to change or rescale as a result of congressional action, but we hope to continue as much of this program as we have funding to accomplish. We will continue to have a coherent, wide ranging program with the resources available to us.

Open Access This article is distributed under the terms of the Creative Commons Attribution 4.0 International License (http://creativecommons.org/licenses/by/4.0/), which permits unrestricted use, distribution, and reproduction in any medium, provided you give appropriate credit to the original author(s) and the source, provide a link to the Creative Commons license, and indicate if changes were made. 


\section{Appendix: Relevant Documentation on Education and Communication}

R. Christensen and G. Knezek, Fab@School evaluation report: Transmedia Space Communications Unit (2013)

NASA, Science Mission Directorate Policy: Policy and Requirements for the Education and Public Outreach Programs of SMD Missions, January 28, 2010, SMD Policy Document SPD-18 (National Aeronautics and Space Administration, 2010)

NASA, Science Plan for NASA's Science Mission Directorate: 4.2 Heliophysics, (National Aeronautics and Space Administration, 2010)

NASA, Strategic Coordination Framework: A Portfolio Approach (NP-2007-01-456-HQ) (National Aeronautics and Space Administration, 2007)

NASA, Explanatory Guide to the NASA Science Mission Directorate: Education \& Public Outreach Evaluation Factors, Version 3.1, November 2010 (National Aeronautics and Space Administration, 2010)

NASA, Explanatory Guide to Proposal Evaluation Factors for ROSES Program Element: Opportunities in Education \& Public Outreach for Earth and Space Science (EPOESS), Version 1.2 November 2010 (National Aeronautics and Space Administration, 2010)

NASA, Inspiring, Engaging, and Educating the Next Generation of Explorers, NP-201210-910-HQ, http://www.nasa.gov/pdf/718645main_2011_Education_Highlights.pdf (2011)

National Research Council, A Framework for K-12 Science Education: Practices, Crosscutting Concepts, and Core Ideas, ed. by H. Quinn, H. Schweingruber, T. Keller (National Academies Press, Washington, 2012)

National Research Council, Next Generation Science Standards: For States, By States, (National Academies Press, Washington, 2013). Available online from http://www. nextgenscience.org

Office of Science and Technology Policy, Federal STEM Strategic Plan, Committee on Science, Technology, Engineering and Math Education (2013). Available from http://www. whitehouse.gov/sites/default/files/microsites/ostp/stem_stratplan_2013.pdf.

\section{References}

J.L. Burch, R.B. Kalmback, MMS-SMART CSR, Solving Magnetospheric Acceleration, Reconnection, and Turbulence (SMART), (NASA AO 03-OSS-01) H.1 E/PO (National Aeronautics and Space Administration, 2004)

J.L. Burch et al., Magnetospheric multiscale overview and science objectives. Space Sci. Rev. (2015). doi:10.1007/s11214-015-0164-9

Congressional Commission on the Advancement of Women and Minorities in Science, Engineering and Technology Development, Land of Plenty: Diversity as America's Competitive Edge in Science, Engineering and Technology (2000). Retrieved December 29, 2008, http://www.nsf.gov/pubs/2000/cawmset0409/ cawmset_0409.pdf

H.B. Davis, MMS EPO evaluation report (2013)

GSFC, Education and Public Outreach (E/PO) Plan for MMS. GSFC MIS document 461-PROJ-PLAN-0108 (2001)

G. Knezek, R. Christensen, T. Wood, Year 3 quantitative analysis findings for Fab@School (2013)

NASA, iMAGiNETIC Space (Transmedia Book, 2012). Available for free download from: http://mms.gsfc. nasa.gov/epo_imagineticspace_book.html

National Science Foundation, Women, Minorities, and Persons with Disabilities in Science and Engineering, NSF 13-304, Arlington, VA (2013)

P.H. Reiff, C.C. Law, Space Weather. DVD-Rom, Vol. 19 (Rice Space Institute, Houston, 2014). ISBN 9781931-523-479 
P.H. Reiff, C.C. Law, I. Smith, Space Update. DVD-Rom, Version 8.0 (Rice Space Institute, Houston, 2013). ISBN 978-1931-523-530

C. Sumners, P.H. Reiff, “Force 5”, Planetarium Show (Rice Space Institute, Houston, 2010). ISBN 9781931-523-479

L. Zimmerman, S. Spillane, P. Reiff, C. Sumners, Comparison of student learning about space in immersive and computer environments. J. Rev. Astron. Educ. Outreach 1(1), A5 (2014) 